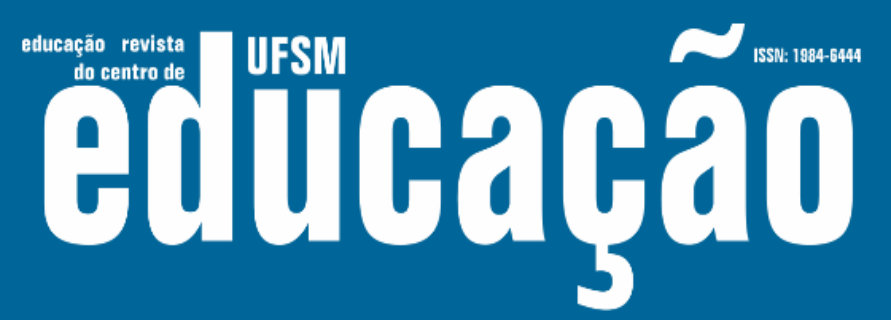

ISSN: 1984-6444 | http://dx.doi.org/10.5902/1984644432874

\title{
Resenha de "Pesquisa em educação comparada sob condições de interconectividade global"
}

Review of "Research in comparative education under conditions of global interconnectivity"

\section{Eduardo Cristiano Hass da Silva}

Doutorando na Universidade do Vale do Rio dos Sinos, São Leopoldo, Rio Grande do Sul, Brasil. eduardohass.he@gmail.com - https://orcid.org/0000-0002-3906-5448

Recebido em 01 de junho de 2018

Aprovado em 30 de agosto de 2018

Publicado em 17 de dezembro de 2019

Jürgen Schriewer é professor emérito de Educação Comparada da Universidade Humboldt, de Berlim, na qual já exerceu as funções de decano da Faculdade de Educação e de coordenador de redes de pesquisa de estudos transculturais nas ciências históricas e sociais. Além disso, é ex-presidente da Sociedade de Educação Comparada da Europa e já foi professor visitante em universidades em Paris, Estocolmo, Tóquio, Beijing, Cidade do México e Buenos Aires. As linhas de pesquisa em que o autor tem atuado são: a História Comparada da Educação, Pesquisa da Sociedade Mundial, História e Metodologia da Pesquisa Social Comparada.

A publicação do livro aqui resenhado coincide com a vinda do professor Jürgen Schriewer à Universidade do Vale do Rio dos Sinos (Unisinos) como pesquisador visitante, abordando o tema "Estudos internacionais e comparados em educação: fundamentos, concepções e metodologias". De forma geral, o autor revisita alguns de seus trabalhos, atualizando textos e apresentando resultados de pesquisas que vem desenvolvendo. Dividido em oito capítulos, o livro mostra-se uma leitura fundamental para aqueles que pretendem se aventurar pelo uso da pesquisa comparada, sobretudo para a pesquisa em educação comparada, entendida pelo autor como resultado da articulação de diferentes campos como a história, filosofia e a sociologia. Ao longo dos capítulos, Schriewer defende a comparação como um exercício complexo. 


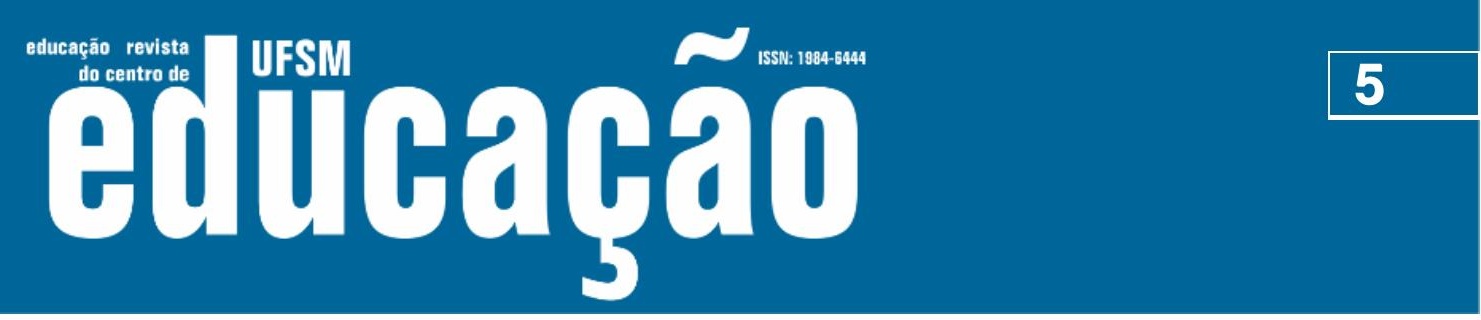

ISSN: 1984-6444 | http://dx.doi.org/10.5902/1984644432874

na Educação Internacional para o Desenvolvimento e na Ciência Política Educacional, sendo que o que as diferenciam são as funções a elas atribuídas.

Os capítulos cinco e seis são voltados para a análise da construção da internacionalidade da educação. O quinto capítulo é escrito em parceria com um segundo autor, Carlos Martinez. Para analisarem as construções da internacionalidade da educação, os autores iniciam apresentando o contexto globalizado de comunicação, atentando para os fenômenos da crescente interconectividade global convencionalmente expressada como 'internacionalização' ou 'globalização'. Para Schriewer e Martinez, o crescimento da interconectividade global tornou-se uma característica proeminente do mundo contemporâneo a partir do final do século $X X$.

No contexto de comunicação globalizada, os autores destacam que diferentes organismos têm interferido e atuado em assuntos educacionais, sendo eles, em especial, o Banco Mundial, a Unesco, a OCDE, bem como ONGs internacionais. Dessa forma, os autores afirmam que a educação tem sido pensada para alguns pesquisadores a partir da lógica do sistema-mundo, entendido “(...) primordialmente em termos de uma 'comunidade política mundial' emergente e um correspondente 'ambiente cultural transnacional' (p. 184). Expressando sua opinião, os autores entendem que a educação é moldada por fatores históricos e culturais, ocorrendo diferenciação funcional da sociedade. Para encerrar o capítulo, apresentam os resultados de um projeto de pesquisa de Educação Comparada da Universidade de Humboldt, de Berlim, realizado a partir de revistas educacionais espanholas, russas e chinesas. O capítulo seis procura basicamente entender as fases dos estudos em educação comparada a partir da lógica do sistema-mundo e de redes de inter-relação, que para Schriewer são duas: "O final do século XVIII e o perfil de um grande programa" e "Final do século XX e mundo como unidade de análise".

Comparados com os demais, os capítulos sete e oito são relativamente breves. O capítulo sete aborda a Declaração de Bolonha de 1999 como "um exemplo particular de processos muito mais amplos de interconexão e padronização em nível global de educação" (p. 259). O autor entende Bolonha como um "mito neoeuropeu", sustentando sua opinião a partir de uma abordagem neoinstitucionalista. Essa 


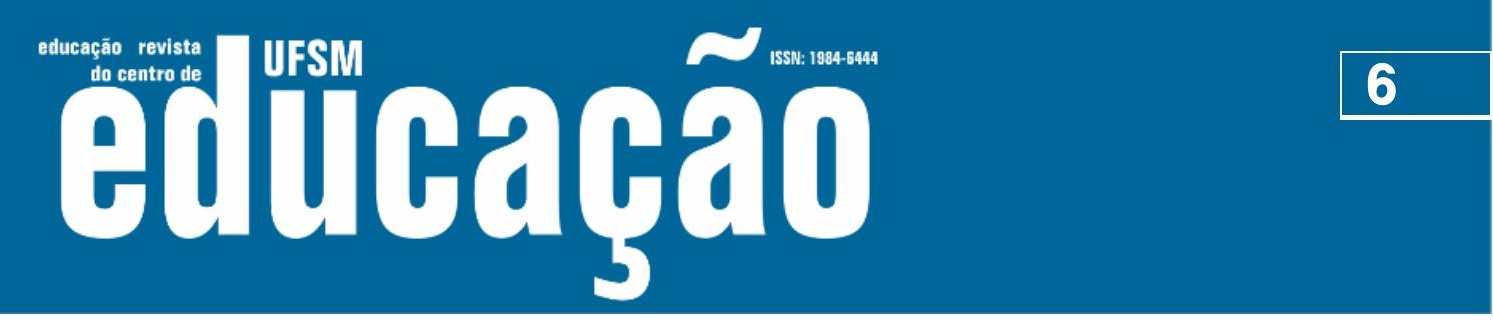

ISSN: 1984-6444 | http://dx.doi.org/10.5902/1984644432874

abordagem é entendida a partir de três argumentos: o primeiro refere-se à "crescente importância alcançada por organizações governamentais e não governamentais internacionais bem como pelos ciclos de comunicação e coordenação bilaterais e multilaterais(...)" (p. 260); o segundo refere-se ao fato de que, em geral, as organizações não determinam seu comportamento primordialmente, "menos ainda exclusivamente, com base em uma tomada de decisões autônoma apropriada para problemas devidamente analisados ou situações problemáticas particulares" (p. 260) e; o terceiro argumento é de que um modelo refinado proporciona novas percepções das condições para processos de difusão transnacional.

Finalizando a obra, o capítulo oito atenta para algumas teorias da sociedade mundial como entidade global, mostrando como as ciências sociais originaram uma gama de teorias refinadas da globalização. A sociedade mundial é entendida como um 'universo simbólico', baseada em uma compreensão construtivista como um sistema baseado em regras cognitivas.

A obra de Jürgen Schriewer é fundamental para compreender a pesquisa em educação comparada a partir de uma perspectiva sócio histórica, uma vez que revela o empreendimento historicamente contingente e intelectual de atuação de importantes atores sociais. O autor apresenta a pesquisa comparada como um campo moldado por diferentes pressupostos epistemológicos, ao mesmo tempo em que incentiva a produção de estudos em educação comparada, visando preencher lacunas e rever trabalhos deficientes. A obra permite a compreensão da pesquisa comparada em uma perspectiva metodológica, complexa e científica, fundamentada na relação de relações e de sistema de relações.

\section{Referência}

SCHRIEWER, Jürgen. Pesquisa em educação comparada sob condições de interconectividade global. Tradução de Geraldo Korndörfer e Luís Marcos Sander. São Leopoldo: Oikos, 2018. 


\section{Tre

ISSN: 1984-6444 | http://dx.doi.org/10.5902/1984644432874

\section{Correspondência}

Eduardo Cristiano Hass da Silva - Universidade do Vale do Rio dos Sinos - Av. Unisinos, 950 - Cristo Rei, CEP 93022-750, São Leopoldo, Rio Grande do Sul, Brasil.

\section{(c) $\underset{\mathrm{EY}}{(\text { ) }(2)}$}

This work is licensed under a Creative Commons Attribution-NonCommercial 4.0 International (CC BY-NC 4.0) 